\title{
Identification of novel genomic regions with aberrant cytosine methylation in hematological malignancies
}

\author{
Yujin Kobayashi ${ }^{1), 2)}$, Kyoko Fujiwara ${ }^{3)}$, Yoshihiro Hatta ${ }^{1)}$, Jin Takeuchi ${ }^{1)}$, Yui Shinojima ${ }^{4)}$, \\ Hiroyuki Kawashima ${ }^{5}$, Jun Igarashi ${ }^{3)}$, Masayoshi Soma ${ }^{3)}$, Hiroki Nagase ${ }^{2), 6)}$ \\ 1) Department of Hematology and Rheumatology, Nihon University School of Medicine, \\ ${ }^{2)}$ Division of Cancer Genetics, Department of Advanced Medical Research Center, Nihon University School of Medicine, \\ ${ }^{3)}$ Division of General Medicine, Department of Medical, Nihon University School of Medicine, \\ 4) Division of Cutaneous Science, Department of Dermatology, Nihon University School of Medicine, \\ ${ }^{5)}$ Department of Pediatric Surgery, Nihon University School of Medicine, ${ }^{6)}$ Chiba Cancer Center Research Institute
}

\begin{abstract}
To identify novel hematologic tumor-specific differentially methylated regions, we performed DNA methylation analysis of 7 new candidate genes (ZAR1, GATA4, CDH22, SOX3, SLC16A5, EHD3 and TBPL1), which has been identified to be aberrantly methylated in human cancers or animal models of human cancer. Bone marrow or peripheral blood samples from 20 patients with leukemia (including $10 \mathrm{AML}$ and $6 \mathrm{ALL}$ ) before treatment and normal lymphocyte cells from 4 healthy individuals as well as eight human leukemia/lymphoma cell lines were used in this study and analyzed with quantitative DNA methylation analysis using the Sequenom MassARRAY system. All four normal control samples showed no or very low level of cytosine methylation in all of the genomic regions examined. However, leukemia/lymphoma cell lines showed frequent hypermethylation of the ZAR1, SLC16A5, EDH3, GATA4, CDH22 and SOX3 genes. DNA hypermethylation of SOX3 was also frequently observed in most of hematologic malignancy cases. Aberrant hypermethylation of ZAR1, GATA4 and $C D H 22$ was also frequently observed in both Philadelphia chromosome positive and negative ALL samples but not in all 10 AML cases. We identified novel genomic regions of ZAR1, GATA4, CDH22 and SOX3 with aberrant cytosine methylation in hematological malignancies. Among those, aberrant DNA methylation of ZAR1, GATA4 and CDH22 may be involved in carcinogenesis of lymphoid populations.
\end{abstract}

Key Words: Aberrant hypermehtylation, hematological malignancies, ALL, AML

(Received September 18, 2012; Accepted December 17, 2012)

\section{Introduction}

DNA cytosine methylation in $\mathrm{CpG}$ dinucleotides is an important epigenetic mechanism and directly involved in the modulation of transcriptional activity and other genome functions. The methylation in $\mathrm{CpG}$-rich promoter regions generally results in transcriptional repression, whereas demethylation plays important roles in transcriptional activation through interaction of transcription factors and/or chromatin-associated protein families. Frequent mutations affecting epigenetic regulators of histone methyltransferases including EZH2 and MLL2, histone demethylases such as UTX and JMJD2C and histone acethyltransferases including CBP and p300 were identified in hematologic malignancies ${ }^{1)}$. Not only

Corresponding authors: Hiroki Nagase, M.D. Ph.D., Chiba Cancer Center Research Institute, 666-2 Nitona-Cho, Chuo-ku, Chiba 260-8717. TEL: +81-43-264-5431 E-mail: hnagase@chiba-cc.jp

Kyoko Fujiwara, Ph.D., Nihon University School of Medicine, 30-1 OyaguchiKamicho, Itabashi-ku, Tokyo 173-8610 TEL: +81-3-3972-8111 E-mail: fujiwara. kyoko@nihon-u.ac.jp genetic mutation but also epigenetic perturbations including aberrant DNA methylation have been described during carcinogenesis of hematopoietic cells ${ }^{2)}$. Thus, both mutations of epigenetic pathway and perturbation of epigenomic state may play important roles in hematologic malignancies.

Aberrant methylation of specific genes, such as BCL6, $C E B P A, P R C 2$ genes, tumor suppressors of $C D K N 2 B$, HOXD 8, MLF1 and PCDH8 has been described in hematological malignancy ${ }^{3,4}$. The development of the technique for genome-wide DNA methylation analysis has allowed us to find perturbed epigenetic patterns including many aberrantly methylated regions in leukemia/ lymphoma, and the reports indicated that some of these aberrantly DNA methylated regions could provide independent predictive value of companion biomarkers for therapeutics, prognostics and survival ${ }^{5,6)}$. Those genomewide surveys of aberrantly methylated genes in leukemia may, however, miss some candidate genes, because of technical pitfalls of the genome wide surveys.

In this report, in order to identify new aberrantly 
Table 1. Patients' characteristics

\begin{tabular}{|c|c|c|c|c|c|c|}
\hline Case & Age & Sex & Diagnosis & FAB classification & Karyotype & $\begin{array}{l}\text { Leukocyte count at diagnosis } \\
\left(/ \mathrm{mm}^{3}\right)\end{array}$ \\
\hline 1 & 56 & $\mathrm{~F}$ & AML & M2 & $46, \mathrm{XX}, \mathrm{t}(8 ; 21)(\mathrm{q} 22 ; \mathrm{q} 22), \mathrm{t}(6 ? ; 9 ?)(\mathrm{p} 23 ? ; \mathrm{q} 34 ?)[3 / 3]$ & 21,000 \\
\hline 2 & 14 & $\mathrm{~F}$ & AML & M2 & $\begin{array}{c}46, \mathrm{XX}, \operatorname{add}(7)(\mathrm{q} 36), \operatorname{del}(8)(\mathrm{q} 12 ?), \\
\operatorname{add}(11)(\mathrm{p} 15), \operatorname{add}(21)(\mathrm{q} 22)[4 / 4]\end{array}$ & 61,000 \\
\hline 3 & 54 & M & AML & M2 & $46, X Y[20 / 20]$ & 4,300 \\
\hline 4 & 59 & $\mathrm{M}$ & AML & M2 & $46, \mathrm{XY}[16 / 16]$ & 400 \\
\hline 5 & 35 & M & AML & M2 & $\begin{array}{l}47, \mathrm{XY}, \mathrm{t}(8 ; 21)(\mathrm{q} 22 ; \mathrm{q} 22) \\
\operatorname{del}(11)(\mathrm{p} 13),+15[10 / 10]\end{array}$ & 59,300 \\
\hline 6 & 42 & $\mathrm{~F}$ & AML & M2 & $\begin{array}{c}46, \mathrm{XX}, \mathrm{t}(8 ; 21)(\mathrm{q} 22 ; \mathrm{q} 22)[17 / 20] \\
46, \mathrm{XX}[3 / 20]\end{array}$ & 16,800 \\
\hline 7 & 35 & $\mathrm{M}$ & AML & M2 & 46, XY, t(7;11)(p15;p15) [18/18] & 25,300 \\
\hline 8 & 45 & $\mathrm{~F}$ & AML & M3 & $46, \mathrm{XX}, \mathrm{t}(15 ; 17)(\mathrm{q} 22 ; \mathrm{q} 11)[11 / 11]$ & 1,300 \\
\hline 9 & 56 & M & AML & M3 & mitotic figure not obtained $*$ & 2,700 \\
\hline 10 & 48 & $\mathrm{~F}$ & AML & M4Eo & $\begin{array}{c}46, X X, \text { inv }(16)(\mathrm{p} 13 \mathrm{q} 22)[8 / 11] \\
46, \mathrm{XX}[3 / 11]\end{array}$ & 28,700 \\
\hline 11 & & $\mathrm{M}$ & ALL Ph - & L1 & $46, \mathrm{XY}[4 / 4]$ & 95,200 \\
\hline 12 & 52 & $\mathrm{~F}$ & ALL Ph - & L1 & $\begin{array}{c}46, \mathrm{XY}, \operatorname{add}(4)(\mathrm{q} 21), \operatorname{add}(11)(\mathrm{p} 11 ?)[3 / 8] \\
46, \mathrm{XX}[5 / 8]\end{array}$ & 88,400 \\
\hline 13 & 43 & $\mathrm{~F}$ & ALL Ph - & L1 & mitotic figure not obtained & 2,900 \\
\hline 14 & 40 & $\mathrm{~F}$ & ALL Ph - & L2 & 46, XX, t(14?:19?)(q32;q13?) [7/7] & 17,100 \\
\hline 15 & 19 & M & $\mathrm{ALLPh}+$ & L1 & $\begin{array}{c}46, \mathrm{XY}, \mathrm{t}(9 ; 22 ; 14 ; 11)(\mathrm{q} 34 ; \mathrm{q} 11 ; \mathrm{q} 32 ; \mathrm{q} 13), \\
\text { del(17)(p11.2) [16/20] } \\
\text { 45, XY, } \mathrm{t}(9 ; 22 ; 14 ; 11)(\mathrm{q} 34 ; \mathrm{q} 11 ; \mathrm{q} 32 ; \mathrm{q} 13, \\
\operatorname{del}(17)(\mathrm{p} 11.2),-20, \operatorname{add}(21)(\mathrm{q} 12)[4 / 20]\end{array}$ & 265,400 \\
\hline 16 & 61 & $\mathrm{~F}$ & ALL Ph + & L2 & $\begin{array}{l}47, \mathrm{XX},-13, \operatorname{add}(17)(\mathrm{p} 13 ?), \\
\operatorname{del}(22)(\mathrm{q} 11),+2 \mathrm{mar}[1 / 1]\end{array}$ & 14,000 \\
\hline 17 & 21 & M & CML CP & - & $\begin{array}{c}46, \mathrm{XY}, \mathrm{t}(3 ; 7)(\mathrm{p} 21 ; \mathrm{q} 36) \\
\mathrm{t}(9 ; 22)(\mathrm{q} 34 ; \mathrm{q} 11)[9 / 10] \\
46, \mathrm{XY}[1 / 10]\end{array}$ & 9,300 \\
\hline 18 & 24 & $\mathrm{~F}$ & CML CP & - & $46, \mathrm{XX}, \mathrm{t}(9 ; 22)(\mathrm{q} 34 ; \mathrm{q} 11)[5 / 5]$ & 82,500 \\
\hline 19 & 62 & M & CML BC & lymphoid crisis & $\begin{array}{c}46, \mathrm{XY}, \mathrm{t}(9 ; 22)(\mathrm{q} 34 ; \mathrm{q} 11)[17 / 20] \\
46, \mathrm{XY}[3 / 20]\end{array}$ & 169,500 \\
\hline 20 & 67 & $\mathrm{M}$ & T-CLL & - & $46, \mathrm{XY}[8 / 8]$ & 19,700 \\
\hline
\end{tabular}

FAB; French America and British, AML; acute myelogenous leukemia, ALL; acute lymphoblastic leukemia, CML; chronic myelogenous leukemia, $\mathrm{Ph}$; Philadelphia chromosomal translocation, $\mathrm{CP}$; chronic phase, $\mathrm{BC}$; blast crisis

* A PML/RARA fusion signal in $46 \%$ of the cells by fluorescence in situ hybridization

methylated regions in human leukemia/lymphoma, which may have yet to be identified, and to find surrogate endpoint biomarkers for leukemia/lymphoma, we initially selected 7 candidate genomic regions, which were found to be aberrantly methylated regions in the other type of human cancers and animal models of human cancers and have never been reported to be aberrantly methylated in human leukemia. Then we examined DNA samples from hematologic malignancies by a quantitative methylation analysis using base-specific cleavage and mass spectrometry.

\section{Materials and methods}

\section{Sample preparation of human hematologic malignan- cies}

Bone marrow samples from 20 patients with leukemia before treatment were obtained from the Laboratory of Hematology and Rheumatology, Nihon University Itabashi Hospital (Tokyo, Japan). Clinical information of each patient is described in Table 1. Samples were supplemental table 1.

\begin{tabular}{|c|c|c|c|c|}
\hline case & disease name & position & blast $(\%)$ & comment \\
\hline 1 & AML M2 & $\mathrm{BM}$ & 15.2 & \\
\hline 2 & AML $\quad$ M2 & $\mathrm{BM}$ & 50.8 & \\
\hline 3 & AML M2 & $\mathrm{BM}$ & 50.0 & \\
\hline 4 & AML M2 & $\mathrm{BM}$ & 76.2 & \\
\hline 5 & AML M2 & $\mathrm{BM}$ & 51.8 & \\
\hline 6 & AML M2 & $\mathrm{BM}$ & 38.8 & \\
\hline 7 & AML $\quad$ M2t $(7 ; 15)$ & $\mathrm{BM}$ & 34.8 & \\
\hline 8 & APL & $\mathrm{BM}$ & 20.6 & \\
\hline 9 & AML & $\mathrm{BM}$ & 87.8 & \\
\hline 10 & AML M4Eo & $\mathrm{BM}$ & 67.3 & \\
\hline 11 & ALL L1 & $\mathrm{BM}$ & 94.0 & \\
\hline 12 & ALL L1 & $\mathrm{BM}$ & 89.9 & \\
\hline 13 & ALL L1 & $\mathrm{BM}$ & 84.3 & \\
\hline 14 & ALL L2 & $\mathrm{BM}$ & 94.2 & \\
\hline 15 & ALL $\quad \mathrm{Ph}+$ & $\mathrm{BM}$ & 95.7 & \\
\hline 16 & ALL L2 Ph+ & BM & 99.1 & \\
\hline 17 & CML (CP) & $\mathrm{BM}$ & 0.0 & \\
\hline 18 & CML (CP) & $\mathrm{BM}$ & 0.0 & \\
\hline 19 & CML (BC1) & BM & 96.5 & \\
\hline 20 & CLL & PB & 88.0 & WBC 30,100 \\
\hline
\end{tabular}


obtained from bone marrow aspiration or peripheral blood and lymphocyte was separated from plasma of the patients using Lympho Separation Medium. Percent of blastic cells was indicated in supplemental table 1 . Normal lymphocyte cells from four healthy individuals were used as normal controls. A written informed consent was obtained from all patients involved in the study. The study was approved by the Institutional Review Board of Nihon University Itabashi Hospital and Nihon University School of Medicine.

DNA was extracted from cell lines and human tumor specimens by the standard phenol/chloroform purification method or with QIAamp DNAMini Kit (Qiagen, Valencia, CA). 1 $\mu$ g DNAs were extracted from each samples and applied for the methylation analysis.

\section{Selection of candidate aberrant methylated regions}

We have preliminary surveyed tissue specific and developmental specific differentially methylated regions (DMRs) in the mouse genome ${ }^{7}$ as well as tissue specific DMRs in the human ${ }^{8}$. In addition, previous studies have been searched for aberrant methylation in mouse models of human tumor ${ }^{9}{ }^{10)}$, the other animal models ${ }^{11)}$ and the other types of human tumors ${ }^{12-15}$. The search allows us to find candidate aberrantly methylated regions, where differential methylation was identified both in normal tissue development and in some kind of tumors. Among those regions, 58 loci were identified as differentially methylated region in animal models ${ }^{16)}$. Among them, we selected 7 candidate genes (Table 2), whose CpG island structure were conserved between human and mouse and aberrant methylations have not been identified in human hematopoietic malignancies.

\section{Quantitative analysis of DNA methylation}

Bisulfite modification was performed by the sodium bisulfite method with an EZ DNA Methylation-Gold Kit (Zymo Research). The bisulfite-treated genomic DNA was amplified by HotStarTaq DNA Polymerase (Qiagen) $\left(15 \mathrm{~min}\right.$ at $94^{\circ} \mathrm{C}$ followed by 45 cycles of $20 \mathrm{~s}$ at $94^{\circ} \mathrm{C}$, $30 \mathrm{~s}$ at $56^{\circ} \mathrm{C}$, and $1 \mathrm{~min}$ at $72^{\circ} \mathrm{C}$ with a 3 -min final extension at $72^{\circ} \mathrm{C}$ ) with specific PCR primers (Operon Biotechnology).

A Sequenom MassARRAY quantitative methylation analysis using the MassARRAY Compact System (Sequenom) was performed for the quantitative DNA methylation analysis. This system is based on MS for the detection and quantitative analysis of DNA methylation using homogeneous Mass Cleave (hMC), base-specific cleavage and MALDI-TOF MS ${ }^{17)}$. Briefly, genomic DNA (1 mg) was converted with sodium bisulfite using the EZ DNA methylation-Gold kit (Zymo Research). The primers were designed using Methprimer (http:// www.urogene.org/methprimer/index1.html) or Methyl Primer Express1 Software v1.0 (Applied Biosystems).
The primer pairs were designed to span the conserved human genomic region as indicated. Bisulfite-treated DNA (up to $20 \mathrm{ng} / \mathrm{ml}$ ) was amplified using HotStarTaq DNA Polymerase (Qiagen) in a $5 \mathrm{ml}$ reaction volume using PCR primers at a $200 \mathrm{nM}$ final concentration (See Table 2 for primer information). The PCR products were checked by agarose gel electrophoresis. After Shrimp Alkaline Phosphatase treatment, $2 \mathrm{ml}$ of the PCR products were used as a template for in vitro transcription and RNase A Cleavage for the T-reverse reaction, as per the manufacturer's instructions (Sequenom hMC). The samples were desalted and spotted on a 384pad SpectroCHIP (Sequenom) using a MassARRAY nanodispenser, followed by spectral acquisition on a MassARRAY Analyzer Compact MALDITOF MS (Sequenom). The resultant methylation calls were performed by EpiTYPER software v1.0 (Sequenom) to generate quantitative results for each $\mathrm{CpG}$ site or an aggregate of multiple $\mathrm{CpG}$ sites. Twice M.Sss-1-treated DNA was prepared according to the manufacture's protocols (New England Biolabs) at $37^{\circ} \mathrm{C}$ for $1 \mathrm{~h}$ followed by $65^{\circ} \mathrm{C}$ for $20 \mathrm{~min}$ inactivation for $100 \%$ methylation samples. The non-applicable reading and its corresponding site were eliminated in calculation.

\section{Results}

All four normal leukocytes showed less than $25 \%$ methylation level within all examined regions, suggesting demethylation of normal leukocyte DNAs at the candidate genes, while 6 out of 7 candidate regions showed frequent hypermethylation in 8 examined lymphoma/ leukemia cell lines (Table 3 and Supplemental Figure 1a). By the analysis of DNA methylation status of the 7 genes in 20 samples from hematopoietic malignancy patients, hyper-methylation of $S O X 3$ was prominent both in AML and ALL. Six out of 10 AML, all 6 ALL samples showed $50 \%$ or higher methylation level at SOX3 locus. Hyper-methylation of ZAR1, GATA4 and $C D H 22$ were observed in ALL samples. All of 6 ALL showed $50 \%$ or higher methylation level at ZARI locus. Five at GATA4 and 3 at $C D H 22$ were also hyper-methylated. No AML samples reached $50 \%$ or higher methylation level at ZAR1, GATA4 and CDH22. Aberrant methylation was not observed at SLC16A5, EHD3 and TBPL1 in any patients' samples examined.

\section{Discussion}

This study presents new genes showing aberrant hyper-methylation in the human leukemia genome. A large number of aberrantly methylated regions in hematopoietic malignancies have been reported within or close to the gene. At the present time, DNA hypomethylating agents, such as 5-azacitidine and 5-aza-2'-deoxycitidine, 
Table 2.

\begin{tabular}{cccl}
\hline Gene & Localization $($ GRCh37/hg19) & Primer Name & \multicolumn{1}{c}{ Sequence (5'-3') } \\
\hline ZAR1 & chr4:48,492,968-48,493,341 & ZAR1-F & TTAAGGTTTAGAGGAGGGGGAGGT \\
& & ZAR1-R & ACAAAACCAAACCCAAAAAAAACAC \\
GATA4 & chr8:11,566,658-11,566,891 & GATA4-F & GTTTTTTTGAGATGGTGTTAGGGT \\
& & GATA4-R & ATCCAAACCATTATAATCAATTCCCTACA \\
CDH22 & chr20:44,879,951-44,880,228 & CDH22-F & TTGGGGTTTAGGAGTATGGA \\
& & CDH22-R & TCCAAATACTACCTAATAATCC \\
SOX3 & chrX:139,586,021-139,586,308 & SOX3-F & GGTGGTAGGTATATGTTGATTA \\
& & SOX3-R & CCTACAATACAACCCAATAATA \\
SLC16A5 & chr17:73,084,269-73,084,519 & SLC16A5-F & GGATTTAGAAAAGTTTTTTGTTTG \\
& \multirow{2}{*}{ chr2:31,457,288-31,457,571 } & SLC16A5-R & AAACAAACAACTAAAACCTCATACC \\
& EHD3-F & GGTTGGGTTTGGTTTTAGGAGTAGG \\
TBPL1 & chr6:134,274,165-134,274,456 & EHD3-R & AAATTTCTTAAACCCCTCACTCACC \\
& & TBPL1-F & TTGATTTGGGGATTAGGAAG \\
& & Forward-tag & CTCCCCAATCTCCATAAAACT \\
\hline & & aggaagagag
\end{tabular}

Primers used for MassARRAY EpiTYPER

Primers used for PCR amplification of the bisulfite-converted DNA. Each reverse primer has a T7-promotor tag for in vitro transcription (5'-cagtaatacgactcacta tagggagaaggct-3') and the forward primer is tagged with a 10mer to balance Tm (5'-aggaagagag-3').

Table 3. Summary of methylation status of candidate genes at each homologous genomic region analyzed by the EpiTYPER

\begin{tabular}{|c|c|c|c|c|c|c|c|c|}
\hline & & ZARI & GATA4 & $\mathrm{CDH} 22$ & SOX3 & SLC16A5 & EHD3 & TBPLI \\
\hline \multirow[b]{2}{*}{$\begin{array}{l}\text { Location of the } \\
\text { region }\end{array}$} & Chromosome & 4 & 8 & 20 & $\mathrm{X}$ & 17 & 2 & 6 \\
\hline & $\begin{array}{l}\text { Physical map } \\
\text { (bp) }\end{array}$ & $\begin{array}{l}48,492,968- \\
48,493,341\end{array}$ & $\begin{array}{l}11,566,658- \\
11,566,891\end{array}$ & $\begin{array}{l}44,879,951- \\
44,880,228\end{array}$ & $\begin{array}{l}139,586,021- \\
139,586,308\end{array}$ & $\begin{array}{l}73,084,269- \\
73,084,519\end{array}$ & $\begin{array}{l}31,457,288- \\
31,457,571\end{array}$ & $\begin{array}{l}134,274,165- \\
134,274,456\end{array}$ \\
\hline \multicolumn{9}{|c|}{ human samples from leukemia patients } \\
\hline \multirow{10}{*}{ AML } & Case 1 & $29.2 \%$ & $36.3 \%$ & $23.6 \%$ & $53.2 \%$ & $5.3 \%$ & $18.9 \%$ & $7.7 \%$ \\
\hline & Case 2 & $23.0 \%$ & $18.1 \%$ & $19.4 \%$ & $50.1 \%$ & $10.8 \%$ & $16.7 \%$ & $13.7 \%$ \\
\hline & Case 3 & $37.5 \%$ & $26.1 \%$ & $18.8 \%$ & $24.0 \%$ & $17.1 \%$ & $16.9 \%$ & $7.9 \%$ \\
\hline & Case 4 & $31.3 \%$ & $29.7 \%$ & $16.3 \%$ & $18.0 \%$ & $12.2 \%$ & $26.5 \%$ & $7.9 \%$ \\
\hline & Case 5 & $28.7 \%$ & $27.0 \%$ & $34.8 \%$ & $51.2 \%$ & $8.3 \%$ & $15.2 \%$ & $8.7 \%$ \\
\hline & Case 6 & $30.4 \%$ & $41.3 \%$ & $35.6 \%$ & $65.6 \%$ & $6.7 \%$ & $14.1 \%$ & $7.3 \%$ \\
\hline & Case 7 & $42.1 \%$ & $49.0 \%$ & $24.9 \%$ & $45.3 \%$ & $32.3 \%$ & $31.2 \%$ & $?$ \\
\hline & Case 8 & $44.8 \%$ & $30.4 \%$ & $15.0 \%$ & $61.1 \%$ & $12.2 \%$ & $24.8 \%$ & $8.2 \%$ \\
\hline & Case 9 & $48.1 \%$ & $20.3 \%$ & $17.7 \%$ & $26.7 \%$ & $7.5 \%$ & $18.3 \%$ & $6.9 \%$ \\
\hline & Case 10 & $35.3 \%$ & $28.1 \%$ & $18.5 \%$ & $64.2 \%$ & $13.0 \%$ & $24.1 \%$ & $9.7 \%$ \\
\hline \multirow{4}{*}{ Ph-ALL } & Case 11 & $81.9 \%$ & $68.9 \%$ & $63.7 \%$ & $79.3 \%$ & $8.4 \%$ & $16.4 \%$ & $7.4 \%$ \\
\hline & Case 12 & $81.4 \%$ & $65.7 \%$ & $58.1 \%$ & $86.1 \%$ & $25.5 \%$ & $23.8 \%$ & $7.7 \%$ \\
\hline & Case 13 & $50.8 \%$ & $96.0 \%$ & $37.3 \%$ & $88.2 \%$ & $23.5 \%$ & $19.6 \%$ & $?$ \\
\hline & Case 14 & $70.8 \%$ & $71.7 \%$ & $45.8 \%$ & $72.6 \%$ & $14.1 \%$ & $16.5 \%$ & $4.4 \%$ \\
\hline \multirow{2}{*}{$\mathrm{Ph}+\mathrm{ALL}$} & Case 15 & $67.1 \%$ & $43.6 \%$ & $44.0 \%$ & $78.1 \%$ & $27.3 \%$ & $18.4 \%$ & $5.4 \%$ \\
\hline & Case 16 & $71.1 \%$ & $78.0 \%$ & $62.0 \%$ & $77.5 \%$ & $15.7 \%$ & $19.3 \%$ & $7.8 \%$ \\
\hline \multirow{2}{*}{ CML CP } & Case 17 & $39.5 \%$ & $10.7 \%$ & $21.9 \%$ & $21.0 \%$ & $19.5 \%$ & $25.3 \%$ & $32.4 \%$ \\
\hline & Case 18 & $20.1 \%$ & $25.1 \%$ & $13.3 \%$ & $49.0 \%$ & $7.7 \%$ & $20.0 \%$ & $11.6 \%$ \\
\hline CML BC & Case 19 & $79.6 \%$ & $65.3 \%$ & $29.3 \%$ & $56.9 \%$ & $11.8 \%$ & $23.7 \%$ & $?$ \\
\hline T-CLL & Case 20 & $49.1 \%$ & $44.9 \%$ & $31.8 \%$ & $44.1 \%$ & $48.5 \%$ & $55.2 \%$ & $7.8 \%$ \\
\hline \multicolumn{9}{|c|}{ Normal lymphocytes from healthy volunteers } \\
\hline & HV1 & $24.3 \%$ & $19.0 \%$ & $14.0 \%$ & $20.8 \%$ & $17.7 \%$ & $27.8 \%$ & $6.2 \%$ \\
\hline & HV2 & $22.9 \%$ & $15.9 \%$ & $16.8 \%$ & $24.0 \%$ & $20.4 \%$ & $22.7 \%$ & $5.5 \%$ \\
\hline & HV3 & $23.1 \%$ & $15.1 \%$ & $13.0 \%$ & $16.9 \%$ & $15.3 \%$ & $23.6 \%$ & $11.8 \%$ \\
\hline & HV4 & $25.3 \%$ & $17.9 \%$ & $23.9 \%$ & $20.8 \%$ & $8.8 \%$ & $23.7 \%$ & $6.4 \%$ \\
\hline
\end{tabular}

The average methylation levels of the entire target regions are shown. Genes methylated more than $50 \%$ are indicated by gray color. Genome location of each region is shown according to UCSC genome browser, Feb2009 GRCh37/hg19. 


\section{Supplemental Figure 1.}

DNA methylation level at specific loci of leukemia samples analyzed by Sequenom MassARRAY. The epigram shows the percent DNA methylation level of each $\mathrm{CpG}$ site of the target region. Methylation level is shown as a color heatmaps. The yellow circle indicates $100 \%$ methylation, and the red circle is $0 \%$ methylation at each $\mathrm{CpG}$ site. The number of $\mathrm{CpG}$ sites, target sequence length and sample names are shown in each epigram. Supplemental Figure la shows human leukemia/lymphoma cell line results from 8 lymphoma/leukemia cell line DNA samples and 4 healthy volunteer lymphocyte samples as control. Supplemental Figure 1b shows results of 20 human sporadic hematologic malignancies from patients and 4 normal lymphocyte controls from healthy volunteers.

a

$0 \%$ OOOOOOOOOO 100\% Not analyzed:

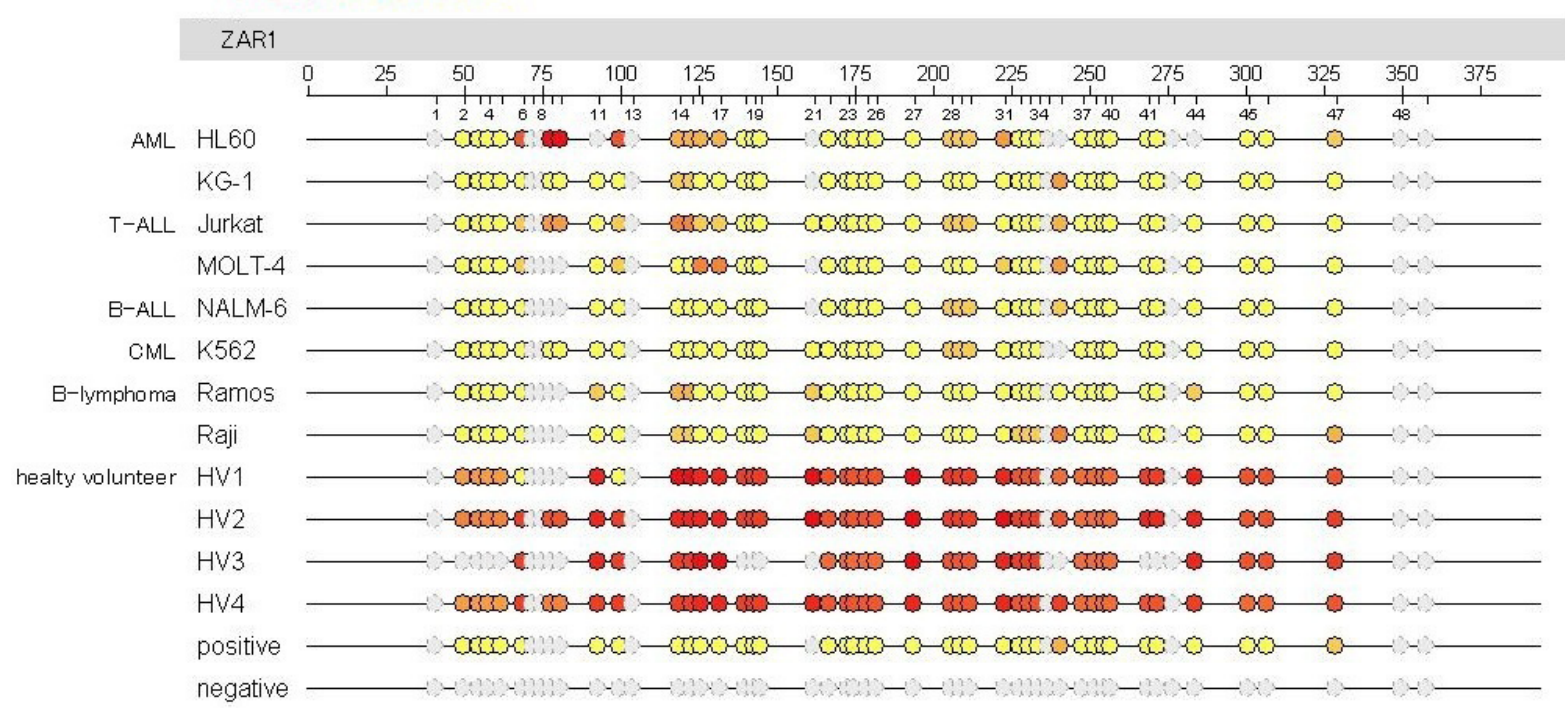

$0 \% \bigcirc 00000000100 \%$ Not analyzed:

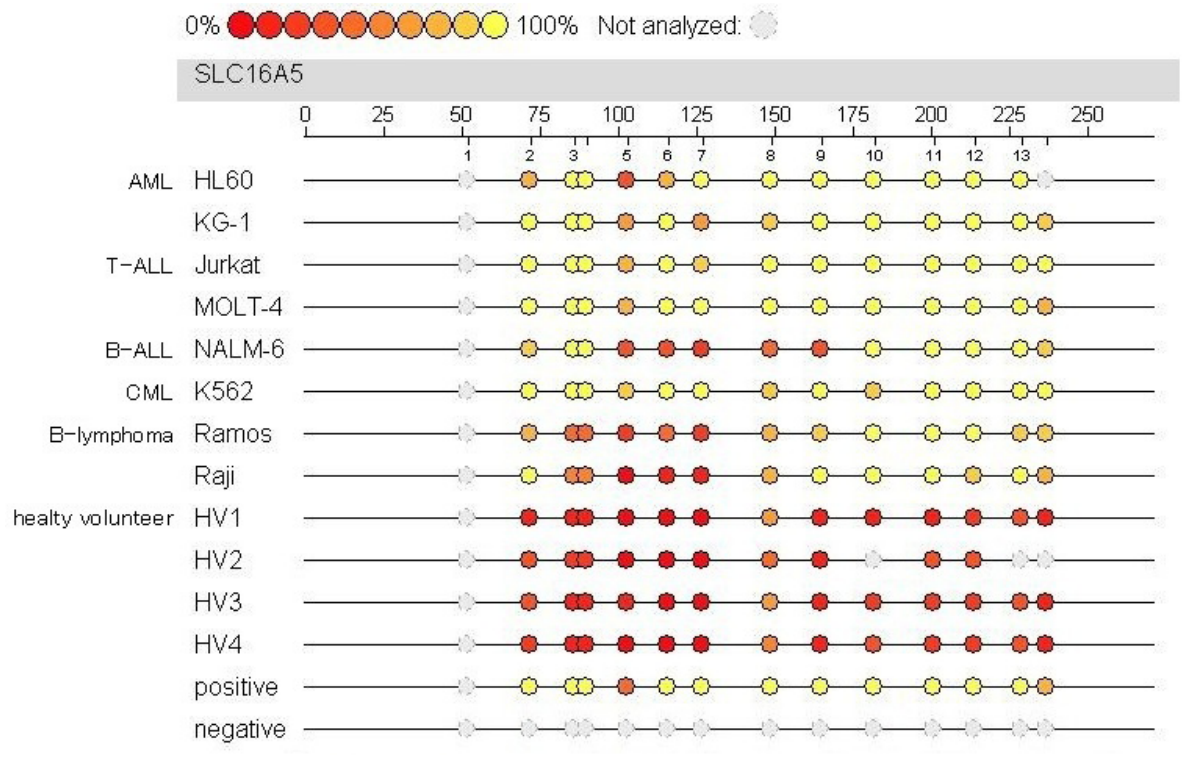


$0 \%$ OOOOOOOOOO 100\% Not analyzed:

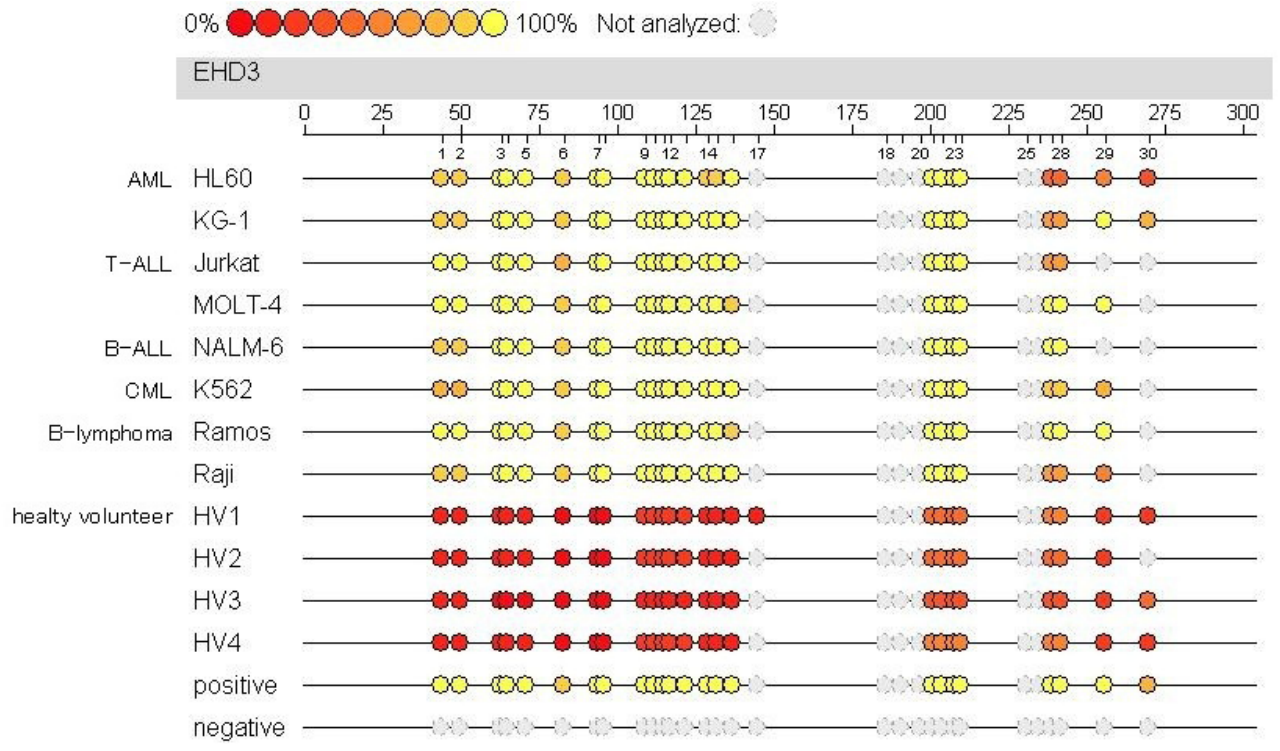

$0 \%$ OOOOOO000 100\% Not analyzed:

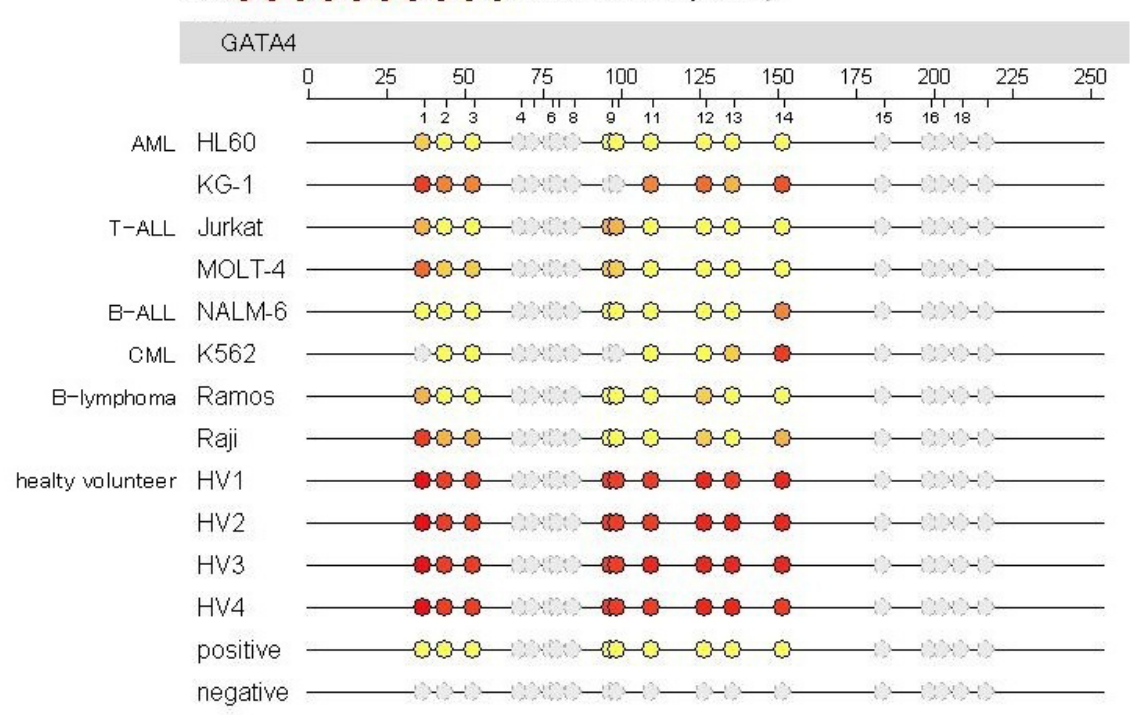

$0 \%$ OON000000 100\% Not analyzed:

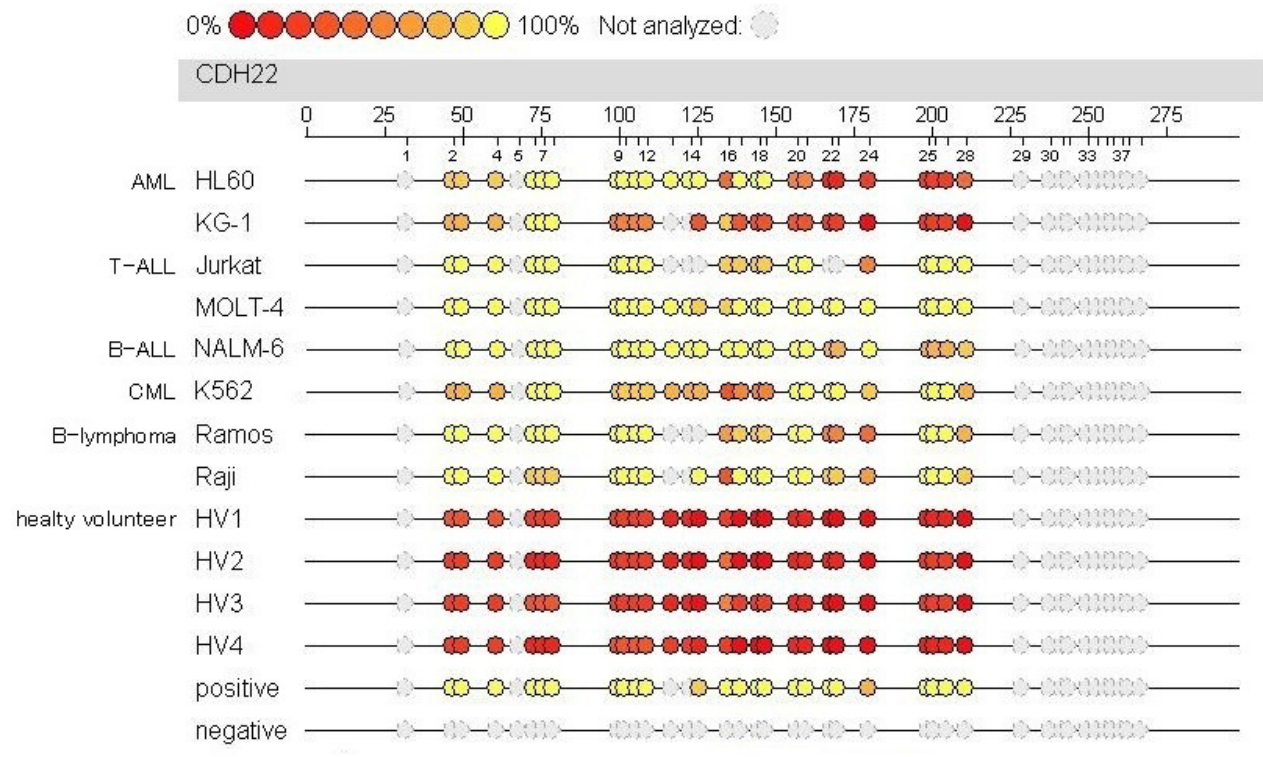


$0 \%$ OOO000000 100\% Not analyzed:

$50 \times 3$

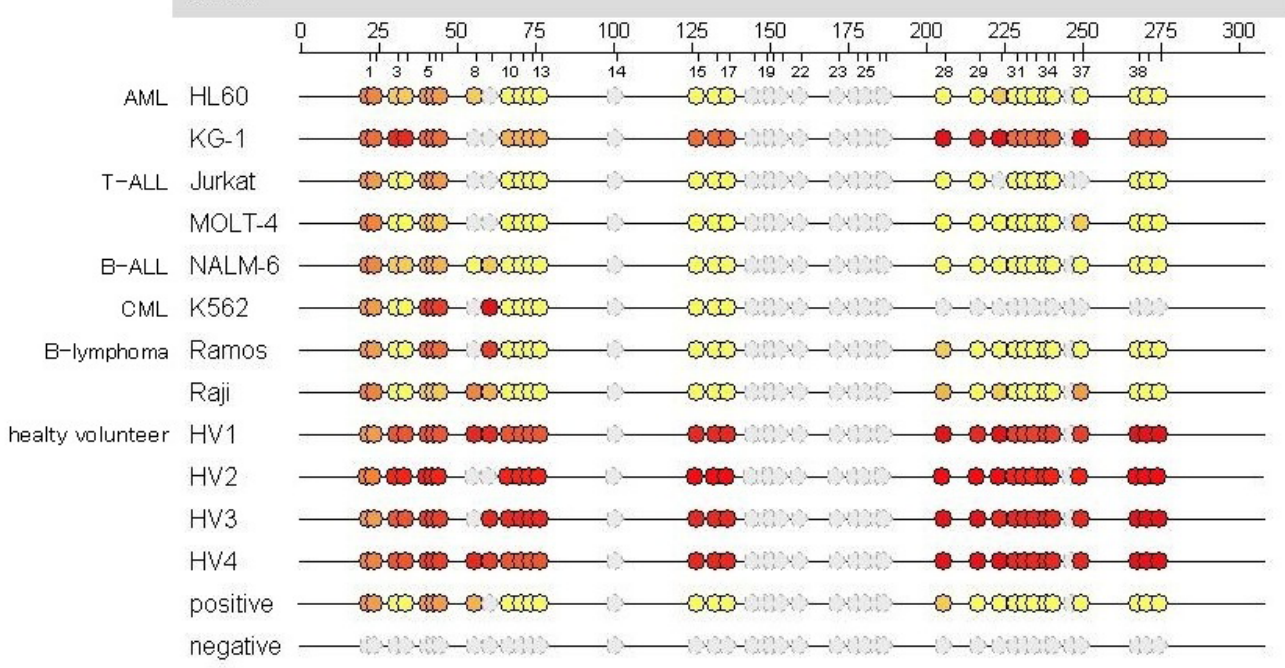

$0 \% 000000000100 \%$ Not analyzed:

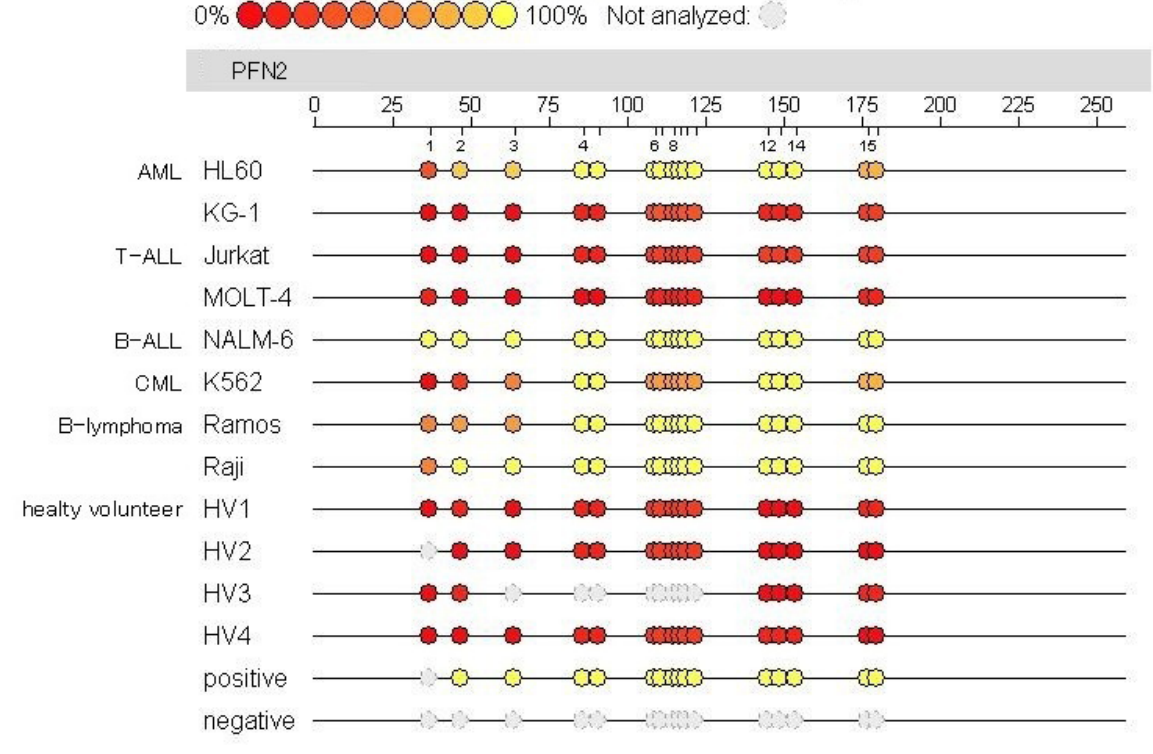

$0 \%$ OOOOOOOOO $100 \%$ Not analyzed:

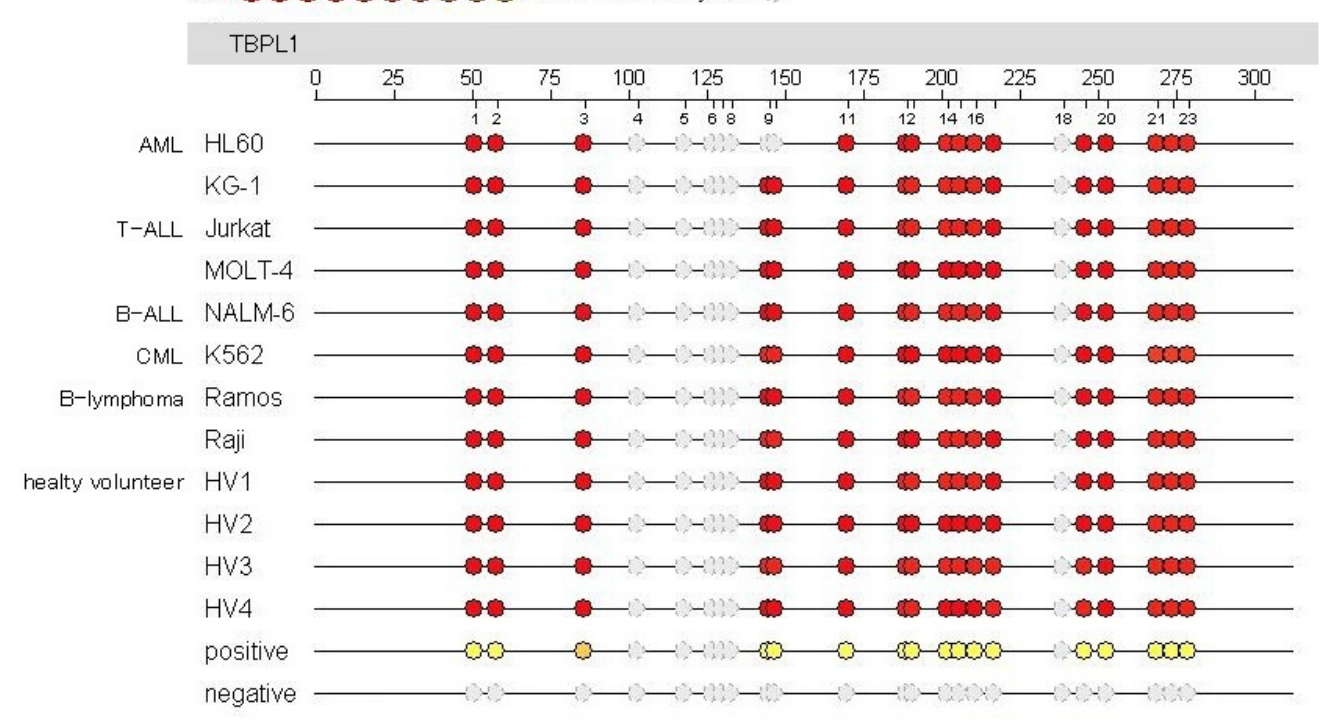




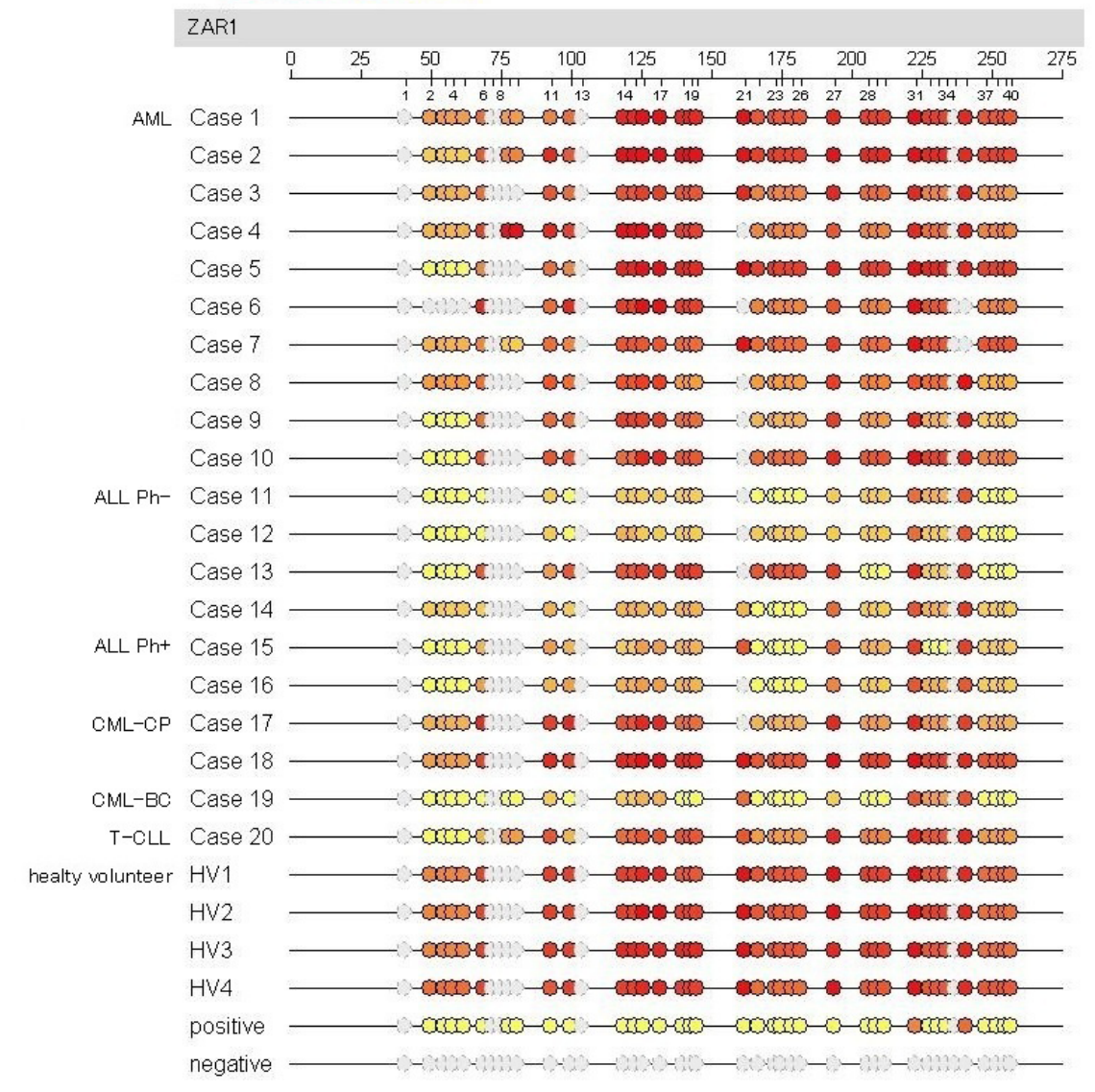

$0 \%$ OOOOOOOOO 100\% Not analyzed:

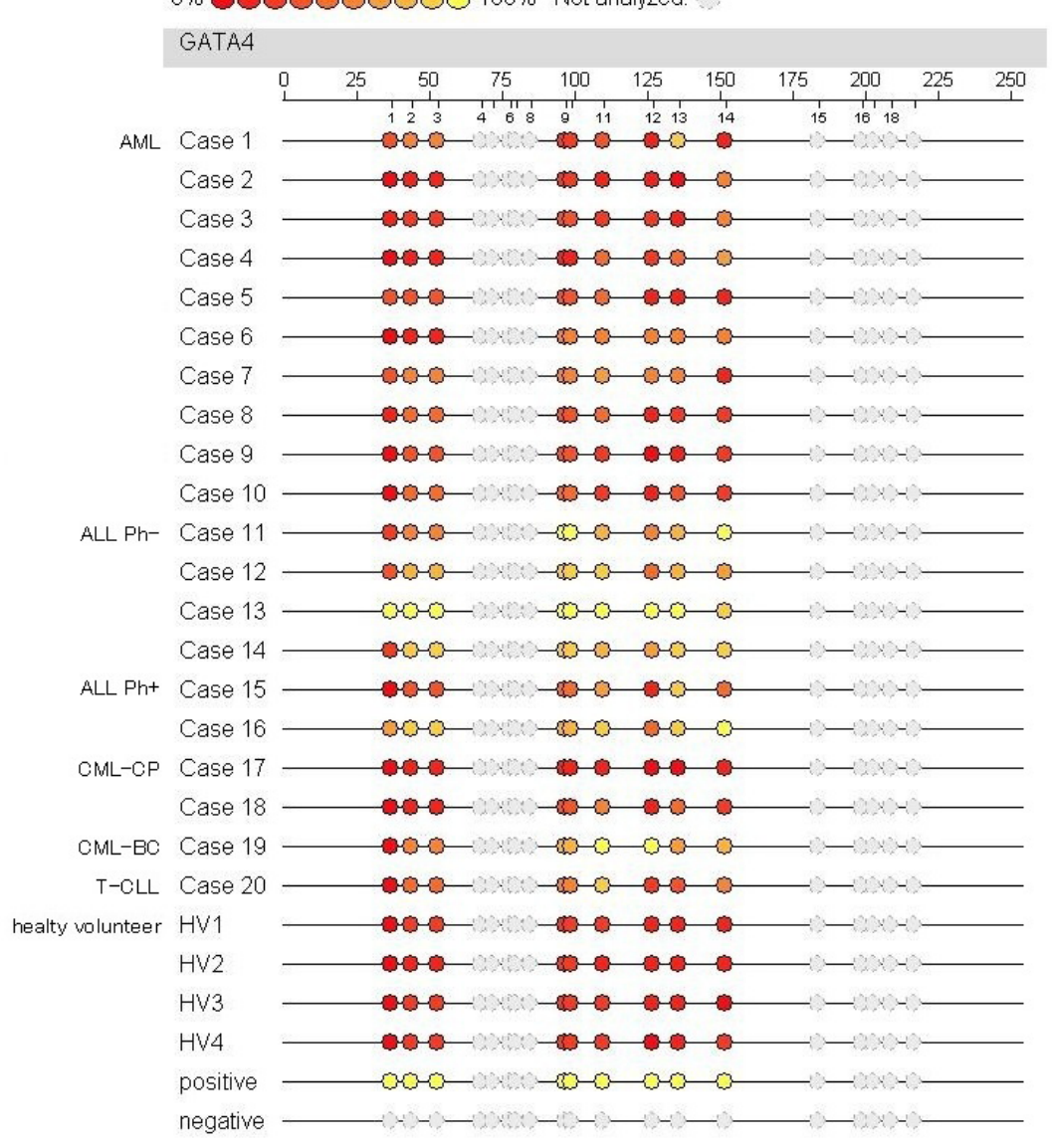


$0 \%$ OOOOOOOOO $100 \%$ Not analyzed:

$\mathrm{CDH} 22$

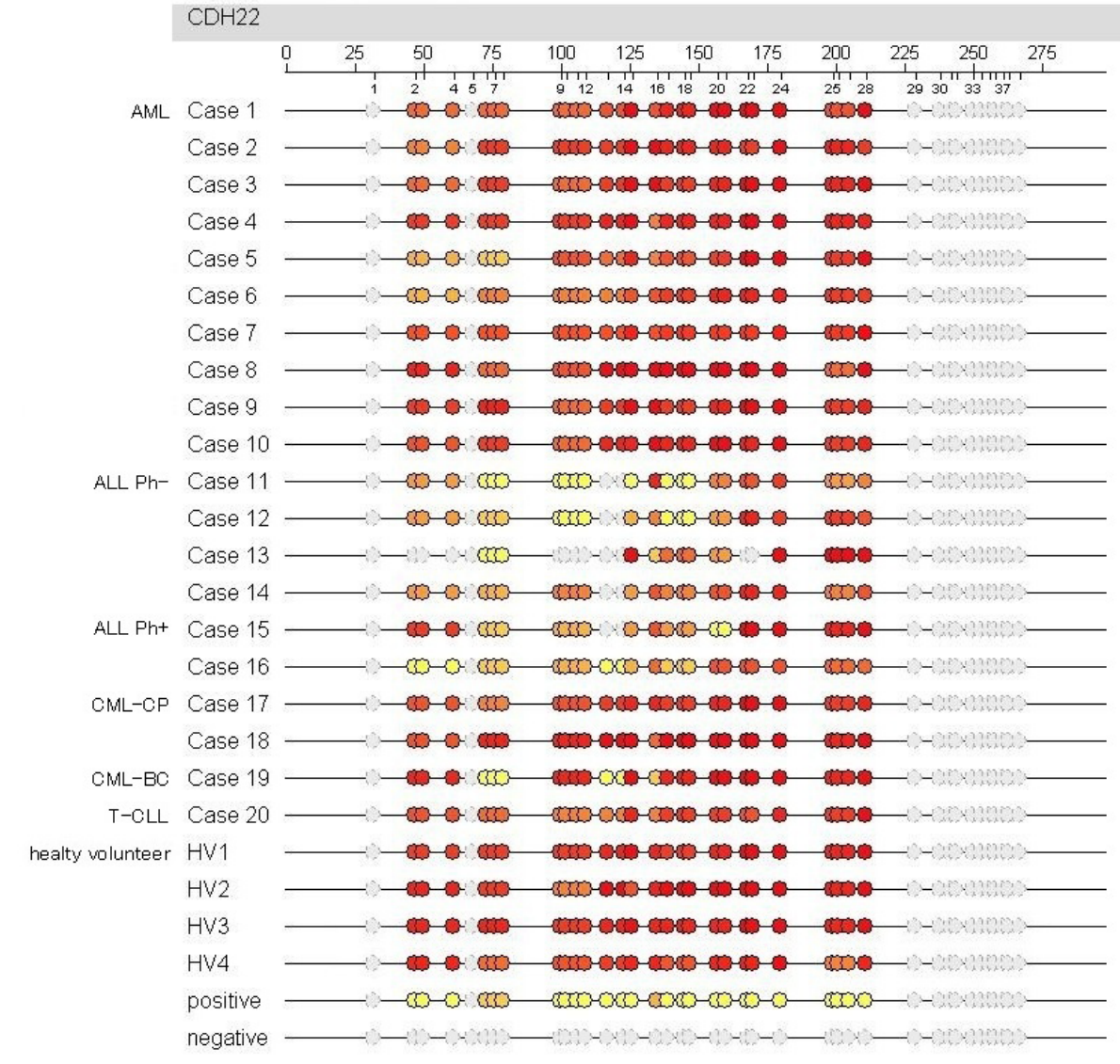

$0 \%$ OOOOOOOOO $100 \%$ Not analyzed:

sox3

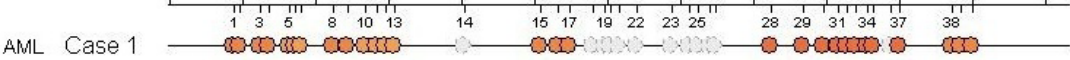

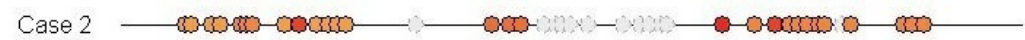

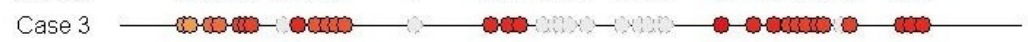

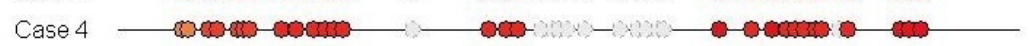

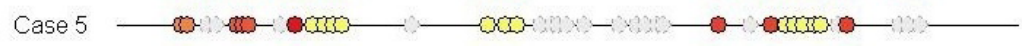

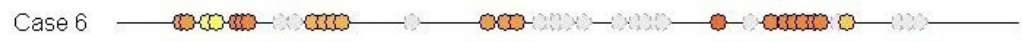

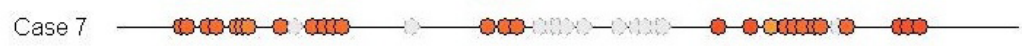

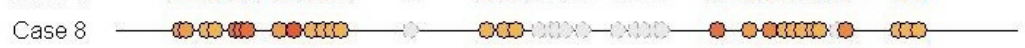

Case $9 \longrightarrow$ -

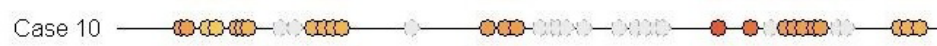

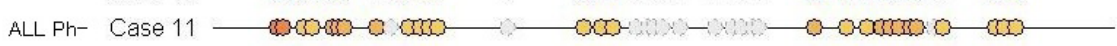

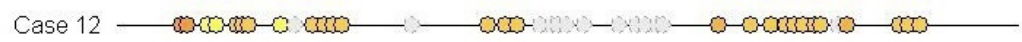

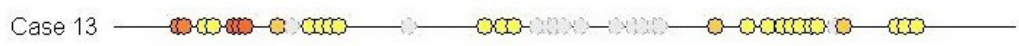

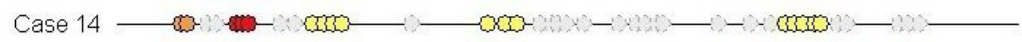

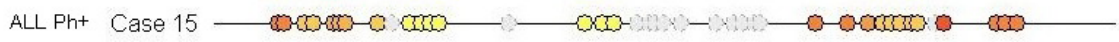

Case $16-000000000-00000000-0 T 0$

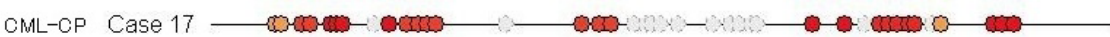

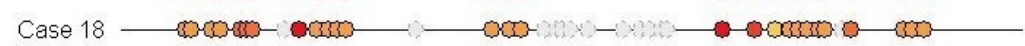

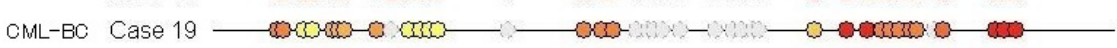

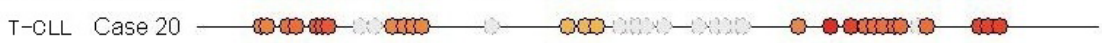

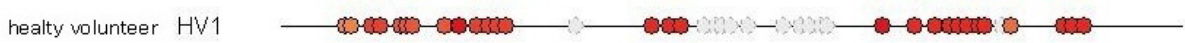

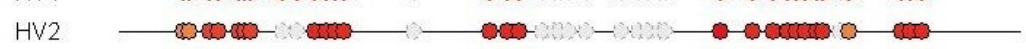

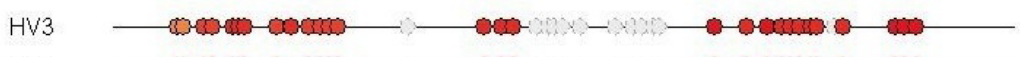

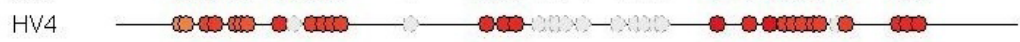

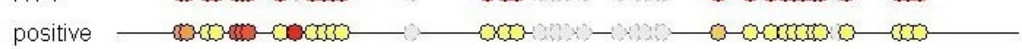

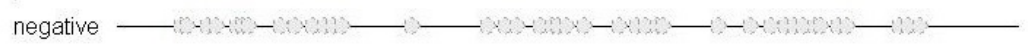


$0 \%$ OOOOO00000 100\% Not analyzed:

EHD3

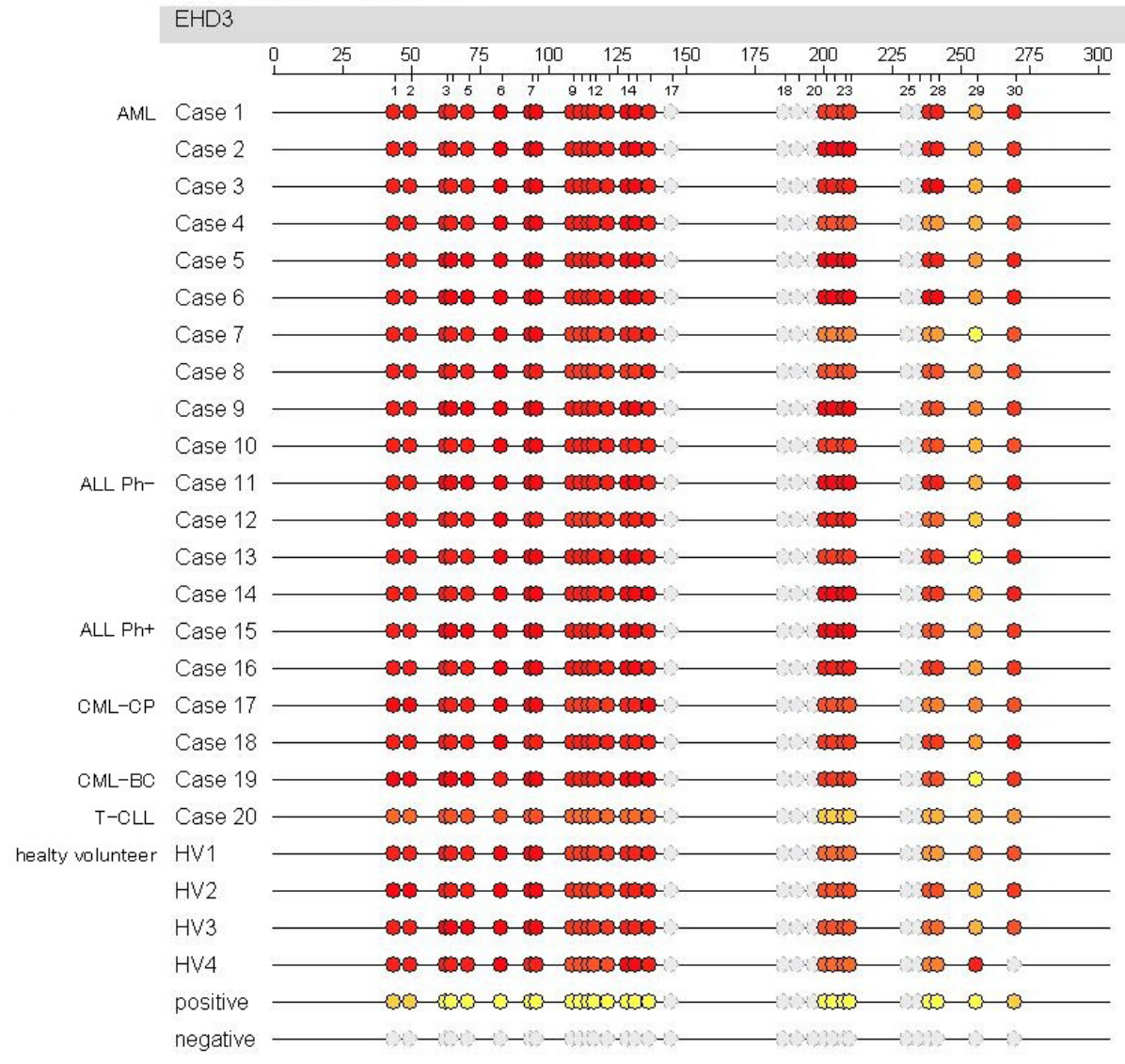

$0 \%$ OOOOOOOOO 100\% Not analyzed:

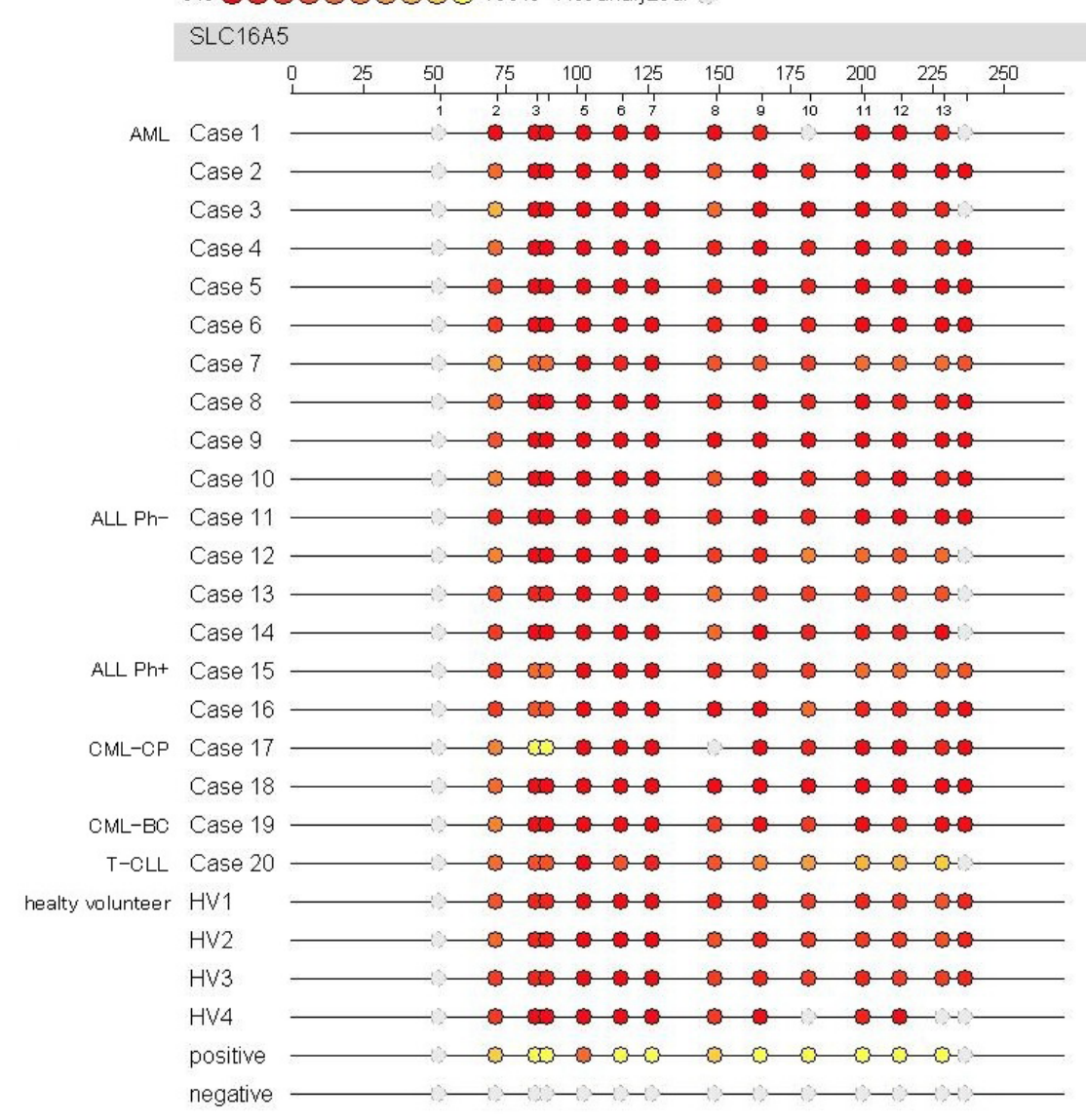


$0 \%$ O00000000 100\% Not analyzed:

PFN2

AML Case 1

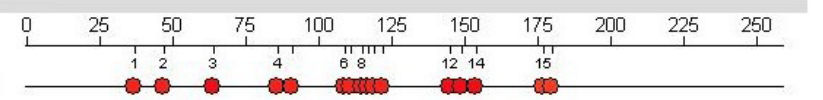

Case 2

Case 3

Case 4

Case 5

Case 6

Case 7

Case 8

Case 9

Case 10

ALL Ph- Case 11

Case 12

Case 13

Case 14

ALL Ph+ Case 15

Case 16

CML-CP Case 17

Case 18

CML-BC Case 19

T-CLL Case 20

healty volunteer HV1

HV2

HV 3

HV4

positive

$\longrightarrow \rightarrow-\rightarrow \rightarrow 0-0$

$\longrightarrow-\rightarrow \rightarrow \infty$

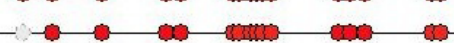

$\rightarrow-0 \rightarrow 0-0$

$\rightarrow-0$ a dim

$\rightarrow \rightarrow 0$ a $\rightarrow 0$

$\rightarrow \rightarrow \rightarrow \infty$

$\longrightarrow$
$\longrightarrow$

negative

$0 \%$ OOOOOOOOOO $100 \%$ Not analyzed:

TBPL1

AML Case 1

$\begin{array}{lllllllllllll}0 & 25 & 50 & 75 & 100 & 125 & 150 & 175 & 200 & 225 & 250 & 275 & 300\end{array}$

Case 2

Case 3

Case 4

Case 5

Case 6

Case 7

Case 8

Case 9

Case 10

125
12

$\longrightarrow$

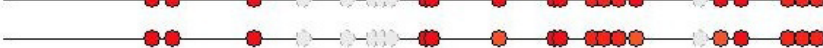

$\longrightarrow-1-1,-0$

-

$\longrightarrow--1,-\rightarrow \longrightarrow-1000$

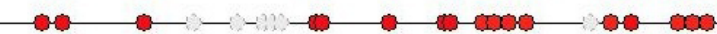

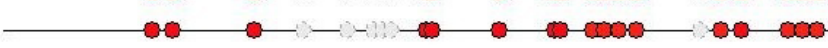

ALL Ph- Case 11

Case 12

Case 13

Case 14

ALL Ph+ Case 15

Case 16

CML-CP Case 17

Case 18

CML-BC Case 19

T-CLL Case 20

healty volunteer $\mathrm{HV} 1$

$\mathrm{H} / 2$

HV 3

HV4

positive
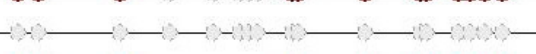

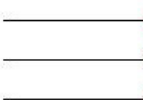

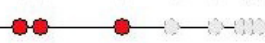

$\rightarrow-1-10000$

$\rightarrow--1 \rightarrow-1000$

$\rightarrow-1,-10-1000$

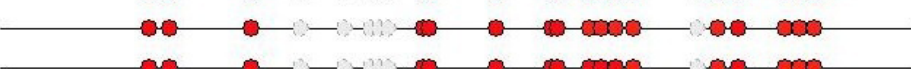

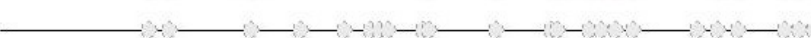

negative

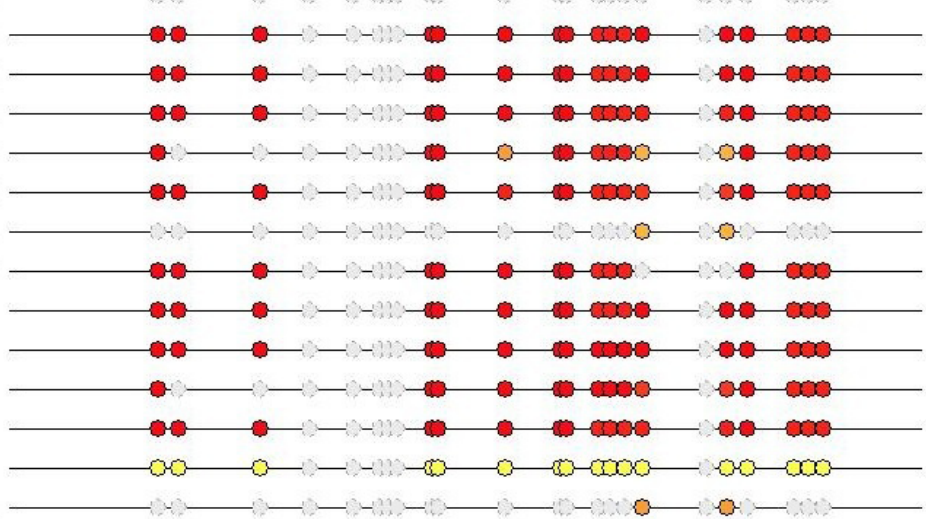


have been used for patients with myelodysplastic syndrome (MDS). The use of these drugs results in DNA hypomethylation and gene re-expression, both in vivo and in vitro. Because hypermethylation of the promoters of certain tumor suppressor genes is prevalent in MDS and AML, it is postulated that the DNA hypomethylation induced by DNA demethylating agents may result in the reactivation of silenced genes, restoring their cancer suppressing functions, and inducing cellular differentiation $^{18)}$. However, most studies have failed to show a relationship between induction of DNA hypomethylation and clinical response. Those facts indicate that there still exist critical unknown genes epigenetically modified in hematological malignancies.

This is the first report to show aberrant methylation of the $S O X 3$ gene in leukemia/lymphoma samples. SOX3 belongs to SOX gene family, encoding transcription factors that act as key regulators of tissue differentiation in embryogenesis. SOXB1 subgroup genes including SOX1, 2 and 3 are widely expressed in neural cells, involved in neural development and differentiation ${ }^{19)}$. Dysfunction of SOX3 protein results in failure of cognitive and pituitary development, leading to mental retardation and growth hormone deficiency in human. Little is known about the involvement of SOX3 in tumorigenesis. Presence of antibodies for SOX3 and the other member of SOXB1 family proteins in the serum of small-cell lung cancer (SCLC) patients have been reported, but the role of SOX3 in SCLC development is still unclear ${ }^{20)}$. It is interesting that the hyper-methylation of SOX3 was observed both in AML and ALL samples, even though two malignant cells develop after the differentiation from hematopoietic stem cell. The result indicates that the aberrant methylation appears in early hematopoietic lineages before those two distinct commitments. In addition this aberrant methylation could be common event to induce malignancy in both AML and ALL.

In the present study, different DNA methylation patterns were observed in ZAR1, GATA4, and CDH22 between AML and ALL samples. Preferential aberrant hypermethylation was observed in ALL rather than AML, although aberrant DNA methylation is a dominant mechanism in MDS progression to AML and abundant in MDS and secondary $\mathrm{AML}^{21,22)}$. Ji $\mathrm{H}$ et al. showed that myelopoiesis and lymphopoiesis result in different terminal DNA methylation patterns and, that myeloid commitment is characterized by less global DNA methylation than lymphoid commitment ${ }^{23)}$. Gaudet F, et al. demonstrated not only that constitutive DNA methylation was required in the establishment and maintenance of the hematopoietic stem cell (HSC) self-renewal program, but they showed also hypomethylated HSCs intrinsically lack lymphoid developmental potential, whereas they maintain normal myeloid and megakaryoerythroid potential $^{24)}$. Although the mechanism of stem cell differ- entiation and development of leukemic cell (or probable leukemic stem cell) could be different, some DNA methylation pattern might be associated with leukemiagenesis and its differentiation to myeloid or lymphoid populations. Aberrant DNA methylation of ZAR1, GATA4, and $C D H 22$ may be associated with differentiation to lymphoid populations of leukemic stem cell.

ZAR1 and GATA4 are known to be involved in fetal development. For instance, ZAR1 is engaged in oocyteembryo transition, and GATA4 is expressed in yolk sac and associated with heart formation. However, little is known about its role in hematological malignancies. Hyper-methylation of the ZARI genes in human melanomas and brain tumors were reported recently. Shinojima et al. noted a very high frequency of hypermethylation of the ZAR1 intergenic region in human melanomas, in contrast to non-methylation in both normal human epidermal melanocyte cell lines and melanocytic nevus surgical specimens ${ }^{9)}$. Watanabe et al. reported that hypermethylation of ZARl in various types of human brain tumors ${ }^{25)}$.

Seven candidate aberrantly methylated genomic regions, which have yet to be identified by whole genome scan, were analyzed in this study. In four out of seven candidate genes aberrantly methylated in leukemia have been identified. This high frequent detection could be because we screened candidate genes based on the evidence obtained from previous studies in both human and animal model of human cancers. Even though there are some limitations in the study using animal models, there are several advantages, as they have a uniform genetic background, could be kept in a controlled environment, and prone to develop tumors of the same etiology. Those merits let us find out new human candidate genes, which have not been found by the whole genome scan analysis and may be a surrogate marker for clinical endpoints. Since our present data clearly showed that the candidate loci found in the analysis of mouse tumor samples were also aberrantly methylated in human leukemia samples, we are planning to explore more genomic region in DNA methylation and gene expression based on the analysis of mouse tumor samples. Further comparative genomic analysis may elucidate a critical unknown gene epigenetically modified in hematological malignancies.

\section{Reference}

1) Shaknovich R, Melnick A. Epigenetics and B-cell lymphoma. Curr Opin Hematol. 2011; 18(4): 293-299.

2) Esteller M. Epigenetics in cancer. N Engl J Med. 2008;358(11): 1148-1159.

3) Foran JM. New prognostic markers in acute myeloid leukemia: perspective from the clinic. Hematology Am Soc Hematol Educ Program. 2010; 2010: 47-55.

4) Roman-Gomez J, Jimenez-Velasco A, Agirre $X$, et al. Lack of $\mathrm{CpG}$ island methylator phenotype defines a clinical subtype of T-cell acute lymphoblastic leukemia associated with good prognosis. J 
Clin Oncol. 2005; 23(28): 7043-7049.

5) Deneberg S, Grövdal M, Karimi M, Jansson M, Nahi H, Corbacioglu A, Gaidzik V, Döhner K, Paul C, Ekström TJ, Hellström-Lindberg E, Lehmann S. Gene-specific and global methylation patterns predict outcome in patients with acute myeloid leukemia. Leukemia. 2010; 24(5): 932-941.

6) Figueroa ME, Lugthart S, Li Y, Erpelinck-Verschueren C, Deng X, Christos PJ, Schifano E, Booth J, van Putten W, Skrabanek L, Campagne F, Mazumdar M, Greally JM, Valk PJ, Löwenberg B, Delwel R, Melnick A. DNA methylation signatures identify biologically distinct subtypes in acute myeloid leukemia. Cancer Cell. 2010; 17(1): 13-27.

7) Liang P, Song F, Ghosh S, Morien E, Qin M, Mahmood S, Fujiwara K, Igarashi J, Nagase H, Held WA. Genome-wide survey reveals dynamic widespread tissue-specific changes in DNA methylation during development. BMC Genomics. 2011; 12(1): 231.

8) Igarashi J, Muroi S, Kawashima H, Wang X, Shinojima Y, Kitamura E, Oinuma T, Nemoto N, Song F, Ghosh S, Held WA, Nagase H. Quantitative analysis of human tissue-specific differences in methylation. Biochem Biophys Res Commun. 2008; 376(4): 658-664.

9) Shinojima Y, Terui T, Hara H, et al. Identification and analysis of an early diagnostic marker for malignant melanoma: ZAR1 intragenic differential methylation. J Dermatol Sci. 2010; 59(2): 98-106.

10) Chen SS, Raval A, Johnson AJ, Hertlein E, Liu TH, Jin VX, Sherman MH, Liu SJ, Dawson DW, Williams KE, Lanasa M, Liyanarachchi S, Lin TS, Marcucci G, Pekarsky Y, Davuluri R, Croce CM, Guttridge DC, Teitell MA, Byrd JC, Plass C. Epigenetic changes during disease progression in a murine model of human chronic lymphocytic leukemia. Proc Natl Acad Sci U S A. 2009; 106(32): 13433-13438.

11) Mirbahai L, Yin G, Bignell JP, Li N, Williams TD, Chipman JK. DNA methylation in liver tumorigenesis in fish from the environment. Epigenetics. 2011; 6(11): 1319-1333.

12) Wen XZ, Akiyama Y, Pan KF, Liu ZJ, Lu ZM, Zhou J, Gu LK, Dong CX, Zhu BD, Ji JF, You WC, Deng DJ. Methylation of GATA-4 and GATA-5 and development of sporadic gastric carcinomas. World J Gastroenterol. 2010; 16(10): 1201-1208.

13) Gao W, Kondo Y, Shen L, Shimizu Y, Sano T, Yamao K, Natsume A, Goto Y, Ito M, Murakami H, Osada H, Zhang J, Issa JP, Sekido Y. Variable DNA methylation patterns associated with progression of disease in hepatocellular carcinomas. Carcinogenesis. 2008; 29(10): 1901-1910.

14) Matsusaka K, Kaneda A, Nagae G, Ushiku T, Kikuchi Y, Hino R, Uozaki H, Seto Y, Takada K, Aburatani H, Fukayama M. Classification of Epstein-Barr virus-positive gastric cancers by definition of DNA methylation epigenotypes. Cancer Res. 201; 71(23): 7187-7197.
15) Keshet I, Schlesinger Y, Farkash S, Rand E, Hecht M, Segal E, Pikarski E, Young RA, Niveleau A, Cedar H, Simon I. Evidence for an instructive mechanism of de novo methylation in cancer cells. Nat Genet. 2006; 38(2): 149-153.

16) Smiraglia DJ, Kazhiyur-Mannar R, Oakes CC, et al. Restriction landmark genomic scanning (RLGS) spot identification by second generation virtual RLGS in multiple genomes with multiple enzyme combinations. BMC Genomics. 2007; 8: 446.

17) Ehrich M, Nelson MR, Stanssens P, et al. Quantitative highthroughput analysis of DNA methylation patterns by base-specific cleavage and mass spectrometry. Proc Natl Acad Sci U S A. 2005; 102(44): 15785-15790.

18) Vigil CE, Martin-Santos T, Garcia-Manero G. Safety and efficacy of azacitidine in myelodysplastic syndromes. Drug Des Devel Ther. 2010; 4: 221-229.

19) Nikčević G, Kovačević-Grujičić N, Mojsin M, Krstić A, Savić T, Stevanović M. Regulation of the SOX3 gene expression by retinoid receptors. Physiol Res. 2011; 60 Suppl 1: S83-91.

20) Titulaer MJ, Klooster R, Potman M, Sabater L, Graus F, Hegeman IM, Thijssen PE, Wirtz PW, Twijnstra A, Smitt PA, van der Maarel SM, Verschuuren JJ. SOX antibodies in small-cell lung cancer and Lambert-Eaton myasthenic syndrome: frequency and relation with survival. J Clin Oncol. 2009; 27(26): 4260-4267.

21) Jiang Y, Dunbar A, Gondek LP, Mohan S, Rataul M, O'Keefe C, Sekeres M, Saunthararajah Y, Maciejewski JP. Aberrant DNA methylation is a dominant mechanism in MDS progression to AML. Blood. 2009; 113(6): 1315-1325.

22) Figueroa ME, Skrabanek L, Li Y, Jiemjit A, Fandy TE, Paietta E, Fernandez H, Tallman MS, Greally JM, Carraway H, Licht JD, Gore SD, Melnick A. MDS and secondary AML display unique patterns and abundance of aberrant DNA methylation. Blood. 2009; 114(16): 3448-3458.

23) Ji H, Ehrlich LI, Seita J, et al. Comprehensive methylome map of lineage commitment from haematopoietic progenitors. Nature. 2010; 467(7313): 338-342.

24) Gaudet F, Hodgson JG, Eden A, et al. Induction of tumors in mice by genomic hypomethylation. Science. 2003; 300(5618): 489-492.

25) Watanabe T, Yachi K, Ohta T, et al. Aberrant hypermethylation of non-promoter zygote arrest 1 (ZAR1) in human brain tumors. Neurol Med Chir (Tokyo). 2010; 50(12): 1062-1069. 